\title{
The role of method: some parting thoughts from a departing editor
}

\author{
David W. Stewart
}

Received: 19 June 2009 / Accepted: 19 June 2009 / Published online: 14 July 2009

(C) The Author(s) 2009. This article is published with open access at Springerlink.com

This issue of JAMS marks the end of my term as editor, though I will continue to haunt the journal in the next two issues with papers I have accepted and over a longer time as the papers I have published influence the field and impact thinking and practice in marketing. It has been an interesting and productive 3 years that I have immensely enjoyed. I have had the rare privilege of editing two of Marketing's leading journals. I hope that I have done a better job as a result of my prior experience. I will miss the daily interaction with the extended set of colleagues that is a part of the routine of an editor. I have appreciated the contributions of authors and reviewers who have stimulated my own thinking and introduced me to so many new ideas. I have experienced the vicarious joy of authors whose papers I have accepted for publication, but I am most proud of the kind comments I have received from authors of papers I have rejected.

In thinking about what words I might share in my parting editorial statement I returned to a number of editorials I have offered in past issues of this journal and the Journal of Marketing. I have used up much of what I have to say about the editorial process and I have already offered advice to authors regarding the enterprise of discovery and publication. I have addressed the role of intellectual communities and the place of journals in those communities (Stewart 1999) and the many factors that influence the quality of research and the likelihood of publication (Stewart 2002, 2007, 2008). I have also addressed the more general questions of what constitutes a "contribution" to the field

\section{W. Stewart $(\bowtie)$}

The A. Gary Anderson Graduate School of Management,

University of California, Riverside,

Riverside, CA 92521, USA

e-mail: david.stewart@ucr.edu
(Ladik and Stewart 2008) and the role of theory and theoretical contributions in the marketing literature (Stewart and Zinkhan 2006). I hope these comments will continue to be useful to future generations of scholars.

Having already offered so many thoughts about the intellectual and empirical contributions in marketing and the publication process I had to think for a long time about what I wished to say in parting as editor of JAMS. It then occurred to me that the substance of a presentation I recently made on the topic of multi-method research would be a nice complement to my earlier commentaries. So, I will close with some thoughts about method and its role in discovery. I will punctuate my comments with the thoughts of others who have been significant contributors to the enterprise of science.

Method matters The famed physicist Werner Heisenberg observed: "We have to remember that what we observe is not nature in itself but nature exposed to our method of questioning." Our mode of inquiry influences our results. Our theories and assumptions, whether explicit or implicit, influence where we look, how we look and how we interpret what we see. In marketing, the view from the perspective of a consumer is often very different from the view of a marketing decision maker. What consumers tell us in a long, open-ended interview is often different from what we learn in a structured survey. Observation of behavior may reveal things about a consumer that neither an interview or survey reveals. Such differences do not suggest that any method is better or worse than another. Rather, it suggests the degree to which "findings" tend to reflect method. "Facts" and "truths" are often bound by method. This is the reason it is so dangerous to rely on a single, "preferred" method for discovery. The use of multiple methods to investigate the same phenomenon can create robust "facts" and "truths." 
Common and complementary empirical findings that emerge from different methods of study are far more compelling than single method outcomes. Papers that use multiple methods produce stronger results, larger contributions, and greater impact.

The role of serendipity The prolific science fiction writer Isaac Asimov stated that "The most exciting phrase to hear in science, the one that heralds new discoveries, is not 'Eureka!' (I found it!) but 'That's funny ....'. What he meant by this is that discovery is most profound when it involves something unexpected rather than a finding of something one is already looking for. A finding one is looking for is already heavily method laden and usually involves a high degree of structure in the investigative process. The greater the structure, the less surprising the outcomes in most cases. Surveys and experiments seldom produce really surprising outcomes. This is why observation and qualitative methods are important in marketing. These types of methods do not produce definitive outcomes but they often suggest interesting avenues for research. "That's funny" often is the spark of the most important research contributions. These methods also help identify boundaries, limitations, and complexities in phenomena. It is for this reason that I have long encouraged my students and colleagues to use qualitative tools to inform their research and use them routinely as I develop ideas for research projects. This said, the "Eureka!" moment is still very important and rigorous test must also accompany great discoveries.

Hypotheses do matter While serendipity can produce exciting new insights, those insights will not be compelling until they are transformed into hypotheses that can be submitted to testing by an appropriate method. Thomas Huxley noted that "The great tragedy of Science (is) the slaying of a beautiful hypothesis by an ugly fact." Hypotheses are important. They make testing possible, and successful tests make findings more compelling. Unfortunately, in marketing many hypotheses are tested against the null hypothesis, that is, a test for a difference of some type versus no difference. Such tests are useful but not very interesting. Comparison of hypotheses to the null is far less interesting than a competition among competing hypotheses suggested by the literature. Marketing is such a sufficiently mature discipline that there exist alternative theories and explanations that can be pitted against one another. Such contests are far more informative and interesting than contests involving the null because they can offer support to one of several competing theories and thereby advance theory development.

Overwhelming substance with method P. L. Berger has observed that "In science as in love, too much concentra- tion on technique can often lead to impotence." Some of the least interesting papers I have reviewed have offered an immaculate research design, sophisticated analysis, and pristine results. The problem with these papers is that the substance of the research was lost in the description of the method and one was left wondering whether it was the research design and methodology that produced the results. Influential research focuses on the substantive contribution(s) and avoids losing the substantive contribution in the eloquence of methodology. The contribution of a paper is not assessed by the methodology used but by the substantive findings that are identified.

Persuasive communication matters An important and often neglected element in the methodology of the enterprise of discovery is communication. No matter how important the phenomenon or problem, failure to communicate will bury the idea. Sir Francis Darwin noted that "In science the credit goes to the man who convinces the world, not the man to whom the idea first occurs." Communication is often an afterthought and persuasive writing does not characterize many of the papers that journals receive. Communication is hard work but its principles are not difficult: (1) clearly state what is new, (2) describe in detail what was done and why in terms of method, and (3) be clear about what the new finding means for theory, practice or general knowledge in the field.

Explaining results A weak explanation of the meaning of empirical findings is common in papers submitted for publication. Sir William Bragg observed that "The important thing in science is not so much to obtain new facts as to discover new ways of thinking about them." New facts are important, but they become more compelling when placed in the context of an answer to the question "What do the findings mean?" The answer to this question should include a discussion of the relationship of the new finding(s) to prior research and to theory. It should also address whether method is an influential factor in determining the empirical findings and what the method of research implies about the findings.

A part of the meaning of any individual empirical result is its relationship to prior research. In the words of Henri Poincare: "Science is facts; just as houses are made of stones, so is science made of facts; but a pile of stones is not a house and a collection of facts is not necessarily science." In describing the meaning and significance of empirical results it is important to consider how the finding itself and the methodology used fit a larger pattern: (1) How is the house described?; (2) How would the methods "stone" be described? and (3) What does the methods "stone" contribute?

Tests of hypotheses are often method bound. Therefore it is important to consider the relationship of method to 
hypothesis. Does a particular method bias findings in favor of a positive finding with respect to a given hypothesis? If a competition of theories is involved in a test of a hypothesis does the method employed favor one theory over another?

Embrace ambiguity The outcomes of research often create as many new questions as they answer. For this reason ambiguity is a part of the discovery process. It is also what makes the role of researcher interesting and ongoing. Those seeking certainty probably need to find a less ambiguous vocation. In the words of M. Catmill: "As an adolescent I aspired to lasting fame, I craved factual certainty, and I thirsted for a meaningful vision of human life - so I became a scientist. This is like becoming an archbishop so you can meet girls."

Although ambiguity is inherent in research, method can help resolve ambiguity. Use of different methods can produce convergent and complementary results. Such results increase confidence and make findings more compelling. At the same time, it is important to acknowledge, with honesty, the limitations imposed by method and the ambiguity these limitations create.

Practical implications are secondary Marketing is an applied discipline. We cannot lose sight of linking what we do to practice. However, this does not mean that the research enterprise should be driven by a search for answers to immediate issues and practical answers to management questions. Such answers are the domain of consultants and applied marketing researchers. The best academic research will find application in due course, but a narrow definition of the research question, a dimension of the research method, will assure a narrow research finding. The goal of discovery is breakthrough insight. In the words of Marie Curie:

"We must not forget that when radium was discovered no one knew that it would prove useful in hospitals. The work was one of pure science. And this is a proof that scientific work must not be considered from the point of view of the direct usefulness of it. It must be done for itself, for the beauty of science, and then there is always the chance that a scientific discovery may become like the radium a benefit for humanity."

Open Access This article is distributed under the terms of the Creative Commons Attribution Noncommercial License which permits any noncommercial use, distribution, and reproduction in any medium, provided the original author(s) and source are credited.

\section{References}

Ladik, D. M., \& Stewart, D. W. (2008). The contribution continuum. Journal of the Academy of Marketing Science, 36(2), 157-165.

Stewart, D. W. (1999). "Beginning again: change and renewal in intellectual communities," (Editorial Statement). Journal of Marketing, 63, 2-5.

Stewart, D. W. (2002). "Getting published: reflections of an old editor", (Editorial Statement). Journal of Marketing, 66, 1-6.

Stewart, D. W. (2007). New and improved! A look at the future. Journal of the Academy of Marketing Science, 35, 1-4.

Stewart, D. W. (2008). Academic publishing in marketing: best and worst practices. European Business Review, 20(5), 421-434. Special Issue on Academic Journals and Academic Publishing.

Stewart, D. W., \& Zinkhan, G. (2006). "Enhancing marketing theory in academic research. Journal of the Academy of Marketing Science, 34, 477-480. 